\title{
Academic Library Services for Mexican Americans
}

Academic libraries are being asked to respond to the needs of yet another ethnic minority group, Chicanos-the second largest minority in America. While their demands on the university library may seem confusing, they represent a search for identity and recognition, and a legitimate call for help. Interestingly enough, some institutions have responded with highly imaginative and progressive service programs, and even initiated recruiting projects to encourage Chicanos to work in libraries or become librarians. Other institutions have done little or nothing in this area, merely perpetuating a condition of mistrust and adding to the rhetoric of institutional racism. On the whole, however, it seems appropriate to ventilate whatever anger may exist in the Chicano community toward academic libraries and bring to the attention of this group the types of successful programs that librarians have developed to address their unique needs. Perhaps these programs will also serve as models and encouragement for other academic librarians across this country.

$\mathrm{T}$ HE ACADEMIC LIBRARY, traditionally the support service mechanism for teaching and research programs at institutions of higher learning, is slowly but surely being affected by the dramatic trends of ethnic relations and is being forced to clarify and define its role toward the various minority communities. An undercurrent of frustration among the various minorities has swept through colleges and universities. In the wake of sometimes-violent protests and confrontations, new and urgent issues have been raised on the campus which tend to pull the library into a more active role in supporting the cultural survival and encouraging the equality of

Robert P. Haro is associate university librarian, Edward L. Doheny Memorial Library, University of Southern California. academic opportunity for ethnic minorities.

As of this date, university libraries, particularly those located in the Far West and Southwest, are in danger of being overwhelmed both by the qualitative change in their role with respect to support services to Mexican American studies and by the quantitative burden of literally thousands of new students at all levels who are seeking and demanding new library materials. ${ }^{1}$ What at present is merely a crisis may soon turn into a disaster, if certain inadequacies of university libraries with respect to this minority group are not understood and resolved with appropriate library acquisition and service programs.

Perhaps a brief discussion of the background leading to the present situation will be enlightening. In his excellent article, "Montezuma's children," Philip D. Ortego wrote: 
Only recently have Mexican Americans begun to receive significant attention in this country, though they are the second largest minority group in the nation. They constitute the single largest linguistic group. Most Mexican Americans (seven million) live in the five state area of Texas, New Mexico, Colorado, Arizona and California. The largest single concentration is in Los Angeles. ${ }^{2}$

While Ortego is correct in stating that most of the Mexican Americans live in the Far West and Southwest, two important facts must be borne in mind: 80 percent of the Mexican American population is urbanized, and there are large and growing concentrations of Mexican Americans in metropolitan areas outside of the five aforementioned states. ${ }^{3}$

The ethnic insurgence and pressure for identity has created an activist student sector in the Mexican American community. ${ }^{+}$On many university campuses they number in the hundreds and are kept in an aggressive mood by a small cadre of staff and faculty with a liberal influx of barrio leaders and workers. The appearance of these students has been sudden and their demands on university libraries disturbing. Many library administrators have felt themselves at the point of the lance and have given ground more because of the pressure than because of any understanding of what is occurring in these ethnic universes. The students are making new demands on the academic library that may seem strident, impulsive and economically impossible to some, but in fact they have a core of profound significance for the very future of the ethnic minority groups-Blacks, American Indians, Asian Americans, and Chicanos-and for American society as a whole. ${ }^{\overline{5}}$ University library administrators, where they have been willing to act, have improvised responses to student pressure, some with the aim of gaining time, some with token gestures in the hope that this potentially troublesome and explosive problem may be defused. A minuscule number of library administrators have refused to take any action whatsoever, believing the crisis will pass if ignored.

Just what is it that the Mexican American students demand of the university library? Briefly, most Mexican American students, particularly those with language or educational background problems, realize that their chances of success within as competitive a setting as a university will be greatly reduced if they are not capable of effectively using the library. It is not that it may be helpful or enriching for Chicano students to know about the library; it is simply that it may be impossible for them to succeed without it. There is a peculiar problem in this situation: the sensitivity of Mexican American students to criticism and to failure is even greater than that of the average university student. ${ }^{6}$ They are thus less likely to seek direct assistance from the library staff, or to participate actively or effectively in anything so formidable as some of the currently voguish classroom courses offered in library use and bibliography. To overcome some of the hesitation and uncertainty students may have with regard to the library, three approaches are necessary. First, the library must have the print and nonprint materials necessary to support teaching and research programs related to Mexican American culture. Second, it is necessary for the library to devise a service program that is as self-directed as possible, which requires a minimum of verbal instruction, and which permits the student to proceed at his own pace in understanding and utilizing the library. Third, the use of Mexican American library staff members to work closely with students and faculty in developing the library's collections and service programs is not only desirable but imperative $^{7}$ 
The specific demands that Mexican American students make on the university library may be viewed in six categories: (1) the expansion of library service programs, including training in the use of library materials and reference and research methods; (2) the purchase of appropriate materials to support the unique needs of Mexican American studies programs; (3) the compilation of special bibliographies and research lists; (4) the adaptation of some of these lists and bibliographies to the peculiar academic needs of Chicano students with language or education background problems or weaknesses; (5) the formulation of an outreach policy on the part of library staff to work with a hastily recruited and overworked faculty in the ethnic studies area who may not be as aware of or sensitive to the support services the library can provide; (6) the identification of all appropriate research publications so as to encourage and stimulate innovative teaching and advanced research on the part of promising Chicano students and teaching faculty.

Obviously, additional comments are necessary in regard to each of these categories, particularly if a more precise view of the student-faculty needs and demands is to result. There have been numerous articles about the hesitation that Mexican Americans have in dealing with institutional situations. ${ }^{8}$ It is unfortunate that too few published studies deal with the attitudes and behavior of Mexican American college students toward academic libraries.

Concerning the expansion of library service programs, the experience at the University of California, Los Angeles, might serve as a model. Many of the Chicano students at UCLA come from low income families; many have been recruited through economic opportunity and special urban crisis programs. The UCLA faculty and librarians found many students deficient in an awareness of library use and resources. To address this deficiency, a course was designed that would systematically acquaint the Mexican American students with the resources of the library. ${ }^{9} \mathrm{By}$ consensus, the library staff felt that the students could best be served through a course in library methods established specifically for this minority group. Working closely with the appropriate faculty and articulate students in the Mexican American studies area, the librarians developed a rather extensive manual and guidebook for a course on library use.

The UCLA course attempts to acquaint the student with the reference and research services offered by an academic library. Assignments are specially designed to introduce the students to some of the most frequently-used reference tools. Although somewhat pedestrian at the beginning level, it is structured to allow considerable expansion and the ready inclusion of more sophisticated reference techniques as the student develops a working knowledge of the methodology and basic works. One must remember that, to many of these students, any kind of library is a highly suspicious and unknown institution. ${ }^{10}$ One of the first and most important steps is to overcome the students hesitation and/or passive attitude toward the library. Although the course is relatively new and there has not been sufficient time to allow precise measurement of its effectiveness, preliminary feedback is favorable. Unfortunately, UCLA is one of but five universities currently doing anything in this area.

The second demand that Chicano students make upon a university library relates to the ordering of appropriate library materials to support the unique needs of Chicano studies programs. It is in this area that most academic librarians feel reasonably comfortable and initially most react to the students favorably. No single demand, however, 
is more misunderstood by academic librarians. What is it that Chicano students demand in the way of library materials? Books? Periodicals? Pamphlets? Films? Ephemera? Obviously, all of these. But, because few appropriate inprint materials are available, librarians face the immense task of locating and reviewing an enormous quantity of older materials until more "relevant" items are produced. Furthermore, the existing items are frequently looked upon with dismay by librarians who refer to them as "not scholarly" and therefore unworthy of adding to the university's collection. Closely related is the controversial nature of the materials. Films may serve as a good example. Perhaps the one most frequently demanded by Mexican American students is $\mathrm{I} A m$ Joaquin, a very powerful and dramatic film already the target of much criticism and even censorship within the public library sector. ${ }^{11}$ Should an academic library buy such a film? If it does, who may view the film and where will it be located? Can the students borrow the film for presentation in barrio communities as well as in classroom settings? It is unfortunate that some academic librarians devise procedural problems to defeat the procurement and utilization of a film they glibly agree is highly "worthwhile."

The demand for "relevant" materials by Mexican American students often clashes with the standard operating procedures of a library's order department. It is surprising how attached some academic librarians are to large book jobbers and periodical dealers. Considering the neglect that the available Mexican American publications have received, particularly the serial publications, it is a wonder that even some find their way into university libraries. Too many order librarians are extremely hesitant to order serial publications from "fly-bynight" outfits, as small Mexican American publishers are so often termed.
Many order librarians in fact seldom, if ever, bother to search for a source for these publications if they are not readily available from an established jobber. Somehow these orders are quietly assigned a low priority and relegated to the limbo frequently known as "in process." What this means, however, is that the legitimate cultural expressions of this minority group, at times indispensable for complete portrayal and understanding, are slow to be secured. I will not attempt to deal with the problems associated with the indexing, cataloging, and other technical services necessary to carry these publications through the library and eventually into the hands of the student or faculty member. Suffice it to say that the road is long and the hurdles many.

Assuming that the problems of acquiring the materials have been solved and that a continuous stream is flowing into the library, a third problem surfaces: the compilation of bibliographies and research lists. Because much of the current material relating to Mexican American culture falls into the category of ephemera, special indexes and annotated bibliographies are needed to make it usable. Ideally, the faculty of the Mexican American studies program and the students themselves should be involved in the planning and operation of such efforts. Several western universities have moved in this direction. Few, however, have assigned a fulltime librarian to such a program. At the University of California at Davis campus, an Ethnic Studies librarian's contacts with appropriate departments as well as with the literature are facilitated by the use of students-Black, Chicano, Oriental, and American Indian-who function as book selectors, literature searchers, and linking pins between the library and their respective departments and minority groups. Not only does the library thereby encourage the acquisition of necessary materials, irrespective of 
format, it also hires minority students and thereby earns their appreciation and trust. Although a good first step, what is really needed is a constantlyupdated series of annotated bibliographies.

Closely associated with such a service are the latent problems of language deficiencies and educational background of many Chicano students. A university library should recognize these problems and take appropriate action to assist students so handicapped. But reading lists to identify new materials always seem to be written in either too sophisticated a manner or so simplistically as to embarrass the intended user. Perhaps what is needed is a bilingual publication. At any rate, there is much libraries can do to reach these students, particularly if an expanded service concept is employed with appropriate and sensitive librarians and supporting staff.

While the dominant theme of this paper has revolved around the needs of students, the formulation of special service and support programs for the faculty within Mexican American studies departments is necessary. The rush into Mexican American studies has placed an enormous strain on the limited manpower available to fill teaching and administrative positions in most western universities. Therefore, many of the new instructors hired for actual classroom teaching find themselves hurtled into curriculum design, course planning, and preparation of lectures with little if any previous academic experience. These conditions, especially the latter, add up to what should be a greater reliance on the university library by these instructors, as well as a closer working relationship with librarians. Hence, it is to this frontline teaching sector that specialized library service should be addressed, to take whatever forms can effectively respond to the evident and foreseeable pressures.

Has this in fact occurred? Yes and no.
Certain support services, within a traditional vein, are relatively simple for a university library to provide for a new teaching department. However, where the teaching department is composed of individuals not completely familiar with the capabilities and functionings of a university library, where the types of needed materials are elusive and not available in its collection, and where a demand for Mexican American library staff includes the development of special or even separate collections, the library administration is hard put to react in any fashion other than horror and dismay. While I will not belabor the demands that this cadre of new faculty members makes upon the library, it is important that the actions of the university library both from anticipatory and reactive motives be investigated.

While teaching faculty of Mexican American descent are few, to say the least, there are even fewer Chicano academic librarians. ${ }^{12}$ Where Chicano librarians have been employed to deal exclusively with students and faculty from Chicano studies programs, their efforts have been highly successful, particularly where the library administration has encouraged them to work closely with faculty in the derivation of appropriate bibliographic aids, book collection programs, and other library service projects devoted to the unique needs of this minority group. Given the limited number of Chicano academic librarians, many university libraries successfully employ capable bilingual library clerks to deal directly with students and faculty in the areas of Chicano studies. At best this latter condition can be viewed as a holding operation and can lead to some serious problems for academic libraries. Eventually, if a Mexican American studies department is influential, aggressive, and vociferous, it can intimidate the library administrators into releasing a Mexican American library clerk and begin the de- 
velopment of a separate collection of materials as a departmental collection. Also, various Mexican American studies programs have employed bilingual Chicano clerks to function as librarians in the establishment and development of a library collection independent of the main university library. In fact, several Mexican American studies programs at major universities in the Far West are actively seeking librarians to administer pocket library collections, some of substantial size and scope. ${ }^{13}$ These actions, for all practical purposes, will not only alienate the library from the teaching department, but restrict the possible contacts that faculty and students will have with the main library. So, how does one circumvent and solve this problem?

The key is the cooperative good will of the faculty. This can be secured by a cooperative venture between library administrators and subject-oriented librarians, and the teaching faculty. The first move in establishing this relationship should come from the library.

What kind of support services and what kind of librarians should deal with the faculty? Ideally, one could want a highly flexible reader services division that could restructure its policies and resources to accommodate just such a contingency. Assuming that some administrative latitude is possible because of the library's organizational structure, the place to start is in an opening dialogue between the university librarian and the chairman of the teaching department. This, of course, is almost too simplistic to mention. However, after the initial contact I recommend that the traditional relationship between administrators be abandoned in favor of close personal and professional encounters between the individuals most concerned with the problems, namely the teaching faculty and the line (as opposed to staff) librarians. Initially this may require that upper level library administrators relinquish some of their rela- tionships with the Mexican American studies faculty and even its chairman. What is needed at this stage of the venture is a quick identification of the goals so that the derivation of a problem-solving methodology results. Also, the contacts between faculty and public services librarians seem the most advantageous for the library and probably for the teaching department faculty. This can be an important liaison not only between the university library and the faculty, but between the library and the students in that department. The discussion of subject and bibliographical tools can be a two-way street between faculty and librarians. How?

Historically, librarians have always been considered the curators of books and other library materials. As such, their greatest expertise has been in the role of information processors as opposed to information interpreters. $\mathrm{Li}$ brarians have adopted the policy of providing the answer to a request in preference to providing not only the answer but some training for the client on how to employ self help in a future, similar situation. ${ }^{14}$ This should not be the case with Mexican American studies faculty and students. In many instances academic librarians at several western universities have a much better command of the available resources than the beginning teaching faculty. What a shame if the two did not cooperate and learn from each other! On the other hand, where the faculty member has a good knowledge of the literature and the librarian does not, it behooves the librarian to secure this knowledge.

Whether this rapport is gained through close personal or professional contacts, through classroom observation or participation, or through joint bibliographic projects is not important at this point. What is important is that the library make the first overture to the teaching department, through upper level administrators, and then allow the 
individuals who must work with the conditions and problems to conceptualize a plan of action acceptable to both parties.

From a purely practical perspective the cooperation between faculty and librarians may provide answers to the following:

- What resources, such as a government documents section, does the library maintain that could be a possible source of information?

- Are there cooperative resourcesharing systems that this university library participates in which might serve as alternatives in searching out appropriate information?

- What nonprint materials, such as films, maps, microforms, etc., exist both in the library and on the university campus?

- Are there special research or public service sectors of the university that maintain data banks?

Such a list could be continued at length because once a good academic librarian is given direction and an opportunity to pursue such a project the possibilities increase tremendously. The essential ingredient within this relationship is the continuing contact and cooperation between the librarian and the Mexican American studies faculty, with the objective of sensitizing both parties to needed services and materials. The last aspect of this process, library materials, leads to the final demand that Mexican American students and faculty bring to a university library.

To support adequately a teaching and research program, a university library must identify all appropriate publications relevant to the Mexican American studies curriculum. The questions that will be asked of librarians, and to a lesser extent the teaching faculty, are:
- What is available in the humanities, art, music, literature (drama, novels, poetry) that will be useful to the program?

- Can the Chicano Art Association be recruited to disseminate not only some of their works, but pertinent information?

- What new research is being conducted in the social scienceseconomics, education, sociology, political science-where is it being done and how can it be secured?

- Can the Chicano Press Association be helpful in identifying and reviewing this new material?

Looking first at the role of the library in supporting teaching programs, the accumulation of library materials alone will not suffice in this case. Data and information gathering will not substitute for the substantive evaluation of sources to communicate the realities of the Mexican American's culture, identity, and uniqueness. A quick search through the numerous bibliographies on Mexican American topics will uncover the same writers and works. Most of these bibliographies have been compiled by well-intentioned librarians and academics. Mexican Americans and particularly Chicano faculty and students view with great suspicion some "scholars" who have produced books ostensibly sympathetic to the Mexican American. Through a dialogue with students and faculty members from Mexican American studies programs, or from conversations with librarians who have long been involved in the review of Mexican American literature, librarians can learn to identify the best works in this area..$^{15}$

Librarians should accept as their goals the development of a data bank of information on the Mexican American within the university library. In addi- 
tion to monographic materials and traditional print sources, hard survey data as well as synthesized materials should be sought out and secured by librarians. An example of a well documented study is Ernesto Galarza's Merchants of Labor. ${ }^{16}$ It is a fundamental account of the exploitation of the bracero with the framework of a humanistic text. Academic librarians can be the alert professionals capable of selecting and organizing objective data that will eventually be useful to the creative writer such as Galarza. Future Mexican American dramatists, essayists, novelists, and poets may derive the images and impressions of their culture from the true records that academic librarians saw fit to identify, secure, and preserve.

In the process of securing appropriate materials to support an academic teaching and research program, university librarians have long been reactive forces. Perhaps this is because most librarians have seldom been included in the conceptual stages of curriculum development, a condition resulting from faculty indifference to librarians, and to a lesser degree a lack of interest by librarians themselves. Such a condition however, should not continue as a precedent for new and developing interdisciplinary programs like ethnic studies. Many librarians have long been the only friends minority group students have had on the campus, being the first service agencies to hire them and the first to offer them equality of service without regard to their language, race, or color. The weaknesses that have existed and continue to exist are principally within the administrative levels of university libraries. A few university libraries have seen the desperate needs of these students and faculty have embarked on some highly innovative and beneficial library education and training programs. The future course of action of necessity requires genuine commitment, planning, the use of appropriate manpower, and most important, the willingness of the library administrators to cast aside the traditional role of a reactive and procedurally-oriented service unit and to initiate innovative service concepts.

The education of the Mexican American is at a critical crossroad. Young people in colleges and universities for the past four years have been attempting to implement educational programs within the established structure. Their efforts have not been completely realized. There have been a few librarians who have dedicated themselves to this minority group and have even risked their positions in making radical changes in what can best be called a philosophically-obsolete library concept of service. Many of the issues that revolve around servicing the needs of Mexican American studies are just arising in the library literature. Librarians should be deeply committed to helping these students better themselves and secure the full benefit of their college education.

\section{References}

1. For the purposes of this paper, the term Mexican American will be used to encompass other terms such as Spanish origin, Spanish surnamed, Latinos, Hispanos, Spanish Americans, and Chicanos. The term Spanish speaking will not be used because many of these people do not speak Spanish. Chicano will be substituted for Mexican American to prevent undue repetition and is not meant to have ideological connotations.
2. Philip D. Ortego, "Montezuma's Children," The Center Magazine v. 3, no. 6 (Nov.Dec. 1970) p. 23-31.

3. U.S. Bureau of the Census, Current Population Reports, Population Characteristics "Spanish American Population: November 1969," Series P-20, no. 195, Feb. 20, 1970. Also by the same publisher and within the same series, "Persons of Spanish Origin in the United States: November 1969," Series P-20, no. 213, Feb. 18, 1971. 
4. For a brief but informative discussion of Chicano student demands at western colleges and universities, the reader is referred to p. 207-9 of Armando B. Rendon's book, Chicano Manifesto (New York: Macmillan, 1971).

5. The core curriculum of many ethnic studies programs, particularly for the better Chicano Studies programs, has as its basis a genuine identification of the unique culture and values of specific minority groups. An awareness of the cultural and language differences endemic to Mexican Americans can only help to encourage an understanding of their attitudes and behavior, a condition that will benefit both the dominant society and this minority group.

6. Horacio Ulibarri discusses the problems of educational disorientation in his study, "Social and Attitudinal Characteristics of Spanish-Speaking, ... ." p. 165-66, in Nathaniel N. Wagner and Marsha J. Haug's book, Chicanos: Social and Psychological Perspectives (St. Louis: C. V. Mosby, 1971).

7. As of this date, ten western colleges and universities have employed Mexican Americans as library staff with responsibilities for dealing with Chicano faculty and students. Unfortunately, clerks are easier to find than Chicano librarians.

8. Arnulfo D. Trejo, "Library Needs for the Spanish Speaking," ALA Bulletin, v. 63, no. 8 (Sept. 1969) p. 1079.

9. California, University of, Los Angeles, Library, Chicano Library Program, by Sue Dudley. Los Angeles, 1970 (UCLA Li- brary Occasional Papers, no. 17).

10. Trejo, "Library Needs," p. 1079.

11. I Am Joaquin, an epic poem by Rodolfo Gonzalez, filmed by the Teatro Campesino, Delano, California, 1968.

12. In the five southwestern states, only five Chicano academic librarians were identified by this writer. Two were at universities, one at a four year college, and two at community colleges. Only three of these librarians were actually employed to work with the Chicano students and faculty.

13. Twelve colleges and universities presently have developing Chicano library collections that are neither located in the main library, nor controlled by the library's administration. One major western university even has budgeted a Chicano Bibliographer position in excess of $\$ 20,000$ per year whose responsibility is to a Mexican American Center and is developing its book collection, which is not controlled by the main library.

14. Samuel Rothstein, "Reference Services," $C R L$ v. 22 , no. 1 (Jan. 1961 ), p. 11-18.

15. Three current bibliographies dealing with Chicanos that deserve mention are: Ernie Barrios, Bibliografia de Aztlan; An Annotated Chicano Bibliography (San Diego, Calif.: San Diego State College, Centro de Estudios Chicanos, 1971). Leo Grebler, et al., The Mexican American People (New York: Free Press, 1970), p. 677-742. Montal Systems, Inc., Chicano Resource Materials (Washington, D.C., 1970).

16. Ernesto Galarza, Merchants of Labor (San Jose, Calif.: Rosicrucian Press, 1964). 